EPJ Web of Conferences 100, 04003 (2015)

DOI: $10.1051 /$ epjconf/ 201510004003

(C) Owned by the authors, published by EDP Sciences, 2015

\title{
Parameters affecting of Akkuyu's safety assessment for severe core damages
}

\author{
Yusuf Kavun 1,2,a and Muzaffer Karasulu ${ }^{3}$ \\ 1. Celal Bayar University, Faculty of Art and Science, Department of Physics, 45030, Manisa, Turkey \\ ${ }^{2}$ Akdeniz University, Faculty of Science, Department of Physics, 07058, Antalya, Turkey \\ ${ }^{3}$ Akdeniz University, Faculty of Science, Department of Space Science and Technologies, Antalya, Turkey
}

\begin{abstract}
We have looked at all past core meltdowns (Three Mile Island, Chernobyl and Fukushima incidents) and postulated the fourth one might be taking place in the future most probably in a newly built reactors anywhere of the earth in any type of NPP. The probability of this observation is high considering the nature of the machine and human interaction. Operation experience is a very significant parameter as well as the safety culture of the host nation. The concerns is not just a lack of experience with industry with the new comers, but also the infrastructure and established institutions who will be dealing with the Emergencies. Lack of trained and educated Emergency Response Organizations (ERO) is a major concern. The culture on simple fire drills even makes the difference when a severe condition occurs in the industry. The study assumes the fourth event will be taking place at the Akkuyu NGS and works backwards as required by the "what went wrong " scenarios and comes up with interesting results. The differences studied in depth to determine the impact to the severe accidents. The all four design have now core catchers. We have looked at the operator errors(like in TMI); Operator errors combined with design deficiencies(like in Chernobyl) and natural disasters( like in Fukushima) and found operator errors to be more probable event on the Akkuyu's postulated next incident. With respect to experiences of the operators we do not have any data except for long and successful operating history of the Soviet design reactors up until the Chernobyl incident. Since the Akkuyu will be built, own and operated by the Russians we have found no alarming concerns at the moment. At the moment, there is no body be able to operate those units in Turkey. Turkey is planning to build the required manpower during the transition period. The resolution of the observed parameters lies to work and educate, train of the host nation and exercise together.
\end{abstract}

\section{Introduction}

Conceivable accidents in a Light Water Reactor can be classified as, a) Abnormal Operational Transients; b) Design Basis Accidents; and c) Severe accidents. It is expected that a substantial core damage occurs if not mitigated, material release into the containment may cause over-pressurization and breach of the containment. The severe accident may result in release of fission products to the environment beyond the acceptable limits of known standards (10CFR100) [1]. When it happens you may have a mess in operational peoples hand and requires special training and cultural behavior to deal with it. This requires long training and behavioral attitudes on adherence to procedures to follow, selection and performing the most appropriate action require long training hours workload share among the peers and safety culture of the organization build over the time with several exercises. Level of degradation during severe accidents usually refer to operating crew work habits and control room environment during the accident management while trying to put plant under recovery operation with sufficient enough core cooling water to keep core covered, if the mitigating measures are not effective, a severe accident progresses in the following stages. Three Mile Island (TMI) occurred following the loss of $125-\mathrm{V}$ DC bus 32 followed by an operator error causing total loss of Auxiliary Feed Water (AFW) [6]. The initial abnormal event progressed into a severe accident due to lack of design knowledge by the operators which caused a wrong decision on defeating the $\mathrm{AFW}$ as to not fill the pressurizer. At the time the industry believed that a severe accident was not credible. Since then, there have been many improvements to the safety systems, operations, procedures, control room environment, education and finally On The Job (OTJ) in the nuclear technology. However, severe accidents should not be entirely discounted not just its probability is not zero but it involves a complex technology plus the human factor ${ }^{*}$. In other words, does not matter how fast can the machine (Lamborghini) goes but the driver may not be ready. There have been several analysis and many methodologies on severe accidents that based on several well-known phenomena. Such as; Core, RCS (Reactor

${ }^{\mathrm{a} C}$ Corresponding author : yusufkavun@gmail.com

This is an Open Access article distributed under the terms of the Creative Commons Attribution License 4.0, which permits unrestricted use, distribution, and reproduction in any medium, provided the original work is properly cited. 
Coolant System), Steam Generator (SG) phenomena must be mustered [7]. The summary of these phenomena will be provided in section 2 and operators' safety culture as well as entire organization's attitude towards safety and the established safety culture plays enormous roll in accident evaluation, operator training must require to be revisited.

In this paper we studied all the phenomena but particularly SG phenomenon, because of the design differences among the subject existing PWRs first [8]; Then, we combined the human factor to all of these to conclude that the new comers in the technology with a horizontal SG designs may require to be more attendant in increased probabilities of severe accidents.

Different cultures have shown different behaviors during severe accident conditions on any operations [5]. Carvalho, and his co-workers claim that human factor is culturally differs under conditions depending of their behavior under the pressured situation [3]. They were investigated cultural and cognitive issues related to the work of nuclear power plant operators during their time on the job, in the control room, and during simulator training (emergency situations), in order to show how these issues impact on plant safety. They have modeled the operators' behavior, their work deals with the use of operational procedures, the constant changes in the focus of attention and the dynamics of the conflicting activities. They have observed that the safety implications of the control room operators' cognitive and cultural issues go far beyond the formal organizational structures usually implied. They have found that that the competence required for the operators are concerned with developing the possibility of constructing situation awareness, managing conflicts, gaps and time problems created by ongoing task procedures, and dealing with distractions, developing skills for collaborative work. These are all both developmental, psychological and degree of training and knowledge accumulation by the control room staff.

\section{Methodology and analysis}

The reactor core, coolant system and steam generator phenomena were studied to explain to the structure of the durability and strength. Energy sources, core uncover, melting and relocation are important to RC phenomena. As a result of decay power, some fission products can be gas form after shutdown and thus decreases exponentially as if function of duration. $\mathrm{Zr}$ and Stainless Steel (SS) can cause the oxidation when react oxygen in steam at high temperatures so release energy [5]. As the RCS is unspoiled, generated hydrogen may be distinctive for oxidation. If there is vessel breach and core is relocated into the containment so there will be additional generation of $\mathrm{H}_{2}$. If the Hydrogen concentration increase global combustion of $\mathrm{H}_{2}$ is highly probable. Along with combustion deflagration and detonation cause the damage on concentration. During loss of coolant accident, the failures occurred can combine with blackout and loss of turbine auxiliary feed water pump, core damage compose in two hours [5]. The differences between inner and outer surfaces' maximum temperature of clad can oxidize that molten $\mathrm{Zr}$ penetrates the oxide layer and candles the fuel rods, leaving less $\mathrm{Zr}$ in the upper hot sections. As a result of breached and LOCA (loss of coolant accident) fission products may be escaping the RCS following core damage. The next line of defense is to cool and contain the core in the RCS and reduce the rate of fission product release from RCS. To perform these situations, quenching and coolability of in vessel debris occupies an important place. If the reactor is partially uncovered and temperatures enough for oxidation, providing small amount of water to the core may only aggravate the oxidation process rather than cool the core. The water flow rate must be high enough to accomplish the compensate for decay power and oxidation, remove stored energy in the reactor core due to elevated temperatures in an uncovered core and refill the vessel. The require flow rate to cool down an uncovered core and refill the vessel is shown in the Fig. 1 as three regions.

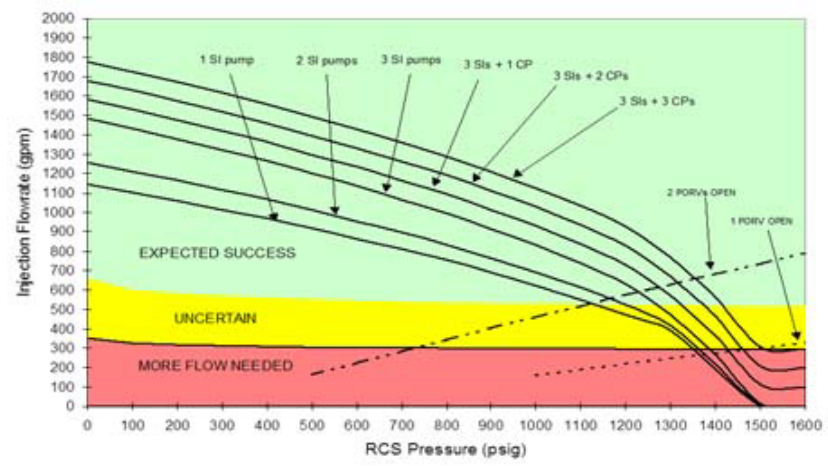

Figure 1: Minimum water injection rate required to recover the water level after the core is uncovered (SAG-2, CA-1) [9].

Region 1: More Flow needed

Region 2: Expected success. Sufficient to cool the reactor core and to reflood the vessel in 45 minutes.

Region 3: Uncertain. Core may be eventually cooled, but it may take as long as 2 hours, during which time the core may already relocate into the lower plenum, compact and lose coolable geometry, and cause a vessel breach.

The required injection flow rate is almost independent of the RCS pressure, whereas the pump flow rates are strongly dependent of the RCS pressure. As the injection is provided, the RCS pressure rises due to evaporation, even if the PORVs (Pilot Operated Relief Valve) are open. The pressure stabilizes at the intersection of the pump curved and PORV curve at the reflood [4]. Also, under thermal attack molten core debris in the lower plenum, two modes of fail will consist of absence of effective cooling [5]. Local Failure may occur through the melting of the instrument guide tubes. If the vessel is pressurized and not submerged, the molten core material may be ejected at a high speed. Creep-rupture failure occurs when a component is subjected for some time interval to high-temperature and high-pressure that need to more than one hour after debris is collected in the lower plenum. Lastly SG phenomena is important to our studies which we will be combined design differences (horizontal vs. vertical) with the mentioned cultural differences. At Akkuyu NPP, AES 2006 design utilizes horizontal steam generators which are traditionally used 
in VVER reactors [2]. The horizontal design means that during SG phenomenon dry out will be reached earlier than the vertical design leading the core meltdown earlier. The horizontal steam generators on the other hand, do not face such problems as primary water stresscorrosion cracking, fouling and denting which are the known problems for the vertical design that leads to SGs degradation the horizontal steam generator also uses a "corridor" layout for the heat-exchange tubes in the tube bundle. Horizontal SG design is a proven design with incremental improvements such as effective sludge removal from the steam generator bottom, the use of secondary side ethanolamine water chemistry and elimination of copper-bearing components on the secondary side, enable an expected service life of 60 years to be achieved. All of the other available 3rd generation PWRs; like Westinghouse's AP1000, Areva's EPR or Ament; Rosatom's AES 2006, and Mitsubishi's AJP1200 are almost the same designs except for some differences in core-fuel, horizontal steam Generators (SG) designs, and some differences in Emergency Response System (ERS) in AES-2006 [2]. Now with the earlier core meltdown due to horizontal SGs of Akkuyu combined with a less experience crew (assumed the operations has been transferred to the local operators with minimal operating experience as well as culture differences). This makes the Akkuyu's risk of a severe accident scenario is somewhat a little bit higher than the other options. The metrics of culture difference requires to be established by the risk analysis. Therefore, the total risk difference has not been qualified in this part of study. The cultural issues focuses on control of MIs (micro incidents) by operators. The operator's attention turns to information while reading signals on identifying if there are overruns. After this moment, the agent focuses on this situation and here is a strong relationship between reading activity, reading instruments, displays etc. [3]. The reading activities provides to strategies for continuously solving problems. To this strategies, operators move to different location to apply instant strategies in the control room. In almost all MI known behaviors of the system by operators that will increase confidence in nuclear power plants. Therefore, to understand the functioning of the system is to realize and what is happening during the operation are one of the most important safety process for NPP.

\section{Conclusion}

In this study, we focused on the adequacy of operational efficiency with the advanced technology of nuclear power plants. Conceivable accidents in a LWR can be classified and mentioned the operational impact for competence of the operator to emphasize just how important. In this process, defined phenomena and safety culture are important to understand how things are going in NPP. As a result of all of them, with respect to experiences of the operators, we do not have any data except for a long and successful operating history of the Soviet design reactors up until the Chernobyl incident. Since the Akkuyu will be built, own and operated by the Russians we have found no alarming concerns at the moment. The plant will be transferred to Turkey when its paid (approximately 15 years), up until that transfer time we cannot make any assumptions as to some serious incidents be taking place, because if it does it will ruin the good reputation of Russians as the best seller of the technology. We assume that Russians will assign their best operators to operate the plant. Turkey is planning to build the required manpower during the transition period. In general, for the host countries the most important issue found was the build up their qualified operating personnel.

\section{References}

[1] J.R. McKinney, A Research Guide to the Federal Register and the Code of Federal Regulations. Law Librarians' Society of Washington, D.C., Issue of Law Library Lights, Vol.46, No.1, p.10-15 (2002)

[2] IAEA, Status of advanced light water reactor designs, Vienna, Austria, (2004)

[3] V.R.P. Carvalho, L.I. dos Santos, M.C.R. Vidal, Safety implications of cultural and cognitive issues in nuclear power plant operation, Applied Ergonomics 37 211-223 (2006)

[4] C.A. Kadak, 22.091/22.903, Nuclear Reactor Safety Lectures, MIT Open Course Ware, http://ocw.mit.edu/terms (Spring 2008)

[5] IAEA, Safety Report Series No 56, Implementation of accident management, Vienna, Austria programmes in nuclear power plants, Vienna, Austria (2008)

[6] TMI, A Report to the Commissioners and to the Public, Washington, D.C., USA (January 1980)

[7] M. Hashim, Y. Ming, A. Saeed, Review of Severe Accident Phenomena in LWR and Related Severe Accident Analysis Codes, ISSN: 2040-7459; eISSN: 2040-7467, China (2013)

[8] P. Tusheva, N. Reinke, Comparative Analyses of Thermal Hydraulic Behavior of VVER-1000/V-320 for a Station Blackout Accident Scenario with ASTEC V1.2.1 and ATHLET 1.2a, Proceedings of Annual Meeting on Nuclear Technology, Karlsruhe, Germany (2007)

[9] IAEA-TECDOC-1440, Overview of training methodology for accident management at nuclar power plants, Vienna, Austria (April 2005) 